\title{
Internacionalização da Educação Superior no oeste catarinense: análise a partir da experiência de uma universidade comunitária
}

\section{Internationalization of Higher Education in western of Santa Catarina: analysis from the experience of a community university}

\section{Internacionalización de la Educación Superior en el oeste de Santa Catarina: análisis desde la experiencia de una universidad comunitaria}

Maria de Lourdes Pinto de Almeida ${ }^{1}$

Silmara Terezinha Freitas ${ }^{1}$

Diego Palmeira Rodrigues ${ }^{1}$

DOI: http://dx.doi.org/10.20435/serie-estudos.v0i0.1384

\begin{abstract}
Resumo: Este texto é fruto de uma pesquisa desenvolvida em rede pelo Grupo Internacional de Estudos e Pesquisas de Educação Superior (GIEPES - UNICAMP), que investiga o processo de internacionalização da Educação Superior no território ibero-americano. O objetivo deste artigo consistiu em mapear e analisar os processos de internacionalização desenvolvidos em uma universidade caracterizada no modelo comunitário, situada no oeste catarinense, a UNOESC. A metodologia científica que norteou esta pesquisa foi a histórico-crítica. Com base nos dados coletados, evidenciou-se que, para a UNOESC, a internacionalização está presente em seus níveis de ensino, pesquisa e extensão. Além disto, a universidade desenvolve pesquisas com outros países, publicações conjuntas com pesquisadores internacionais e participa de redes de investigação. Possui um órgão próprio para a internacionalização, nomeado Coordenadoria de Relações Internacionais, bem como realiza visitas internacionais. A UNOESC está implantando e fortalecendo gradativamente os processos que envolvem a internacionalização.
\end{abstract}

Palavras-chave: internacionalização; Educação Superior; Políticas de Educação Superior.

Abstract: This text is the result of a research developed in network by the International Group of Studies and Research of Higher Education (GIEPES - UNICAMP), which investigates the internationalization process of Higher Education in the Ibero-American territory. The objective of

${ }^{1}$ Universidade do Oeste de Santa Catarina (Unoesc), Joaçaba, Santa Catarina, Brasil. 
this paper was to map and analyze the internationalization processes developed in a university characterized in the community model, located in the west of Santa Catarina, UNOESC. The scientific methodology that guided this research was the historical-critical. Based on the data collected, it was evident that, for UNOESC, internationalization is present in its teaching, research and extension levels. In addition, the university conducts research with other countries, joint publications with international researchers and participates in research networks. It has its own internationalization body, named International Relations Coordination, as well as conducts international visits. UNOESC is gradually implementing and strengthening the processes involving internationalization.

Keywords: internationalization; Higher Education; Higher Education Policies.

Resumen: Este texto es el resultado de una investigación desarrollada en red por el Grupo Internacional de Estudios e Investigación de la Educación Superior (GIEPES - UNICAMP), que investiga el proceso de internacionalización de la Educación Superior en el territorio iberoamericano. El objetivo de este trabajo fue mapear y analizar los procesos de internacionalización desarrollados en una universidad caracterizada en el modelo comunitario, ubicada en el oeste de Santa Catarina, UNOESC. La metodología científica que guío esta investigación fue la histórica-crítica. Con base en los datos recopilados, fue evidente que, para UNOESC, la internacionalización está presente en sus niveles de enseñanza, investigación y extensión. Además, la universidad realiza investigaciones con otros países, publicaciones conjuntas con investigadores internacionales y participa en redes de investigación. Tiene su propio organismo de internacionalización, denominado Coordinación de Relaciones Internacionales, y también realiza visitas internacionales. La UNOESC está implementando y fortaleciendo gradualmente los procesos de internacionalización.

Palabras clave: internacionalización; Educación Superior; Políticas de Educación Superior.

\section{INTRODUÇÃO}

Na contemporaneidade, a globalização tem influenciado vários aspectos de ordem social, econômica, política e tecnológica, atingindo inevitavelmente as Instituições de Ensino Superior (IESs). Neste sentido, discutir e refletir sobre os processos de internacionalização da Educação Superior é ao mesmo tempo uma das principais tendências e também um desafio para as universidades neste início do século XXI, visto que eles estão sendo responsáveis pela integração não só do conhecimento, mas também das relações de cooperação entre as nações.

Nesse cenário, a internacionalização tem ganhado centralidade nas diretrizes educacionais dos países, devido à crescente importância da universidade no fortalecimento das economias nacionais e nos seus processos de desenvolvimento tecnológico e científico. Desta forma, motivada pela influência e pelo financiamento de entidades/organismos internacionais, a internacionalização é incorporada nas políticas de Educação Superior e institucionalizada nas universidades. 
Assim, é desse contexto que emerge a importância em se estudar o desenvolvimento dos processos de internacionalização nas IES, surgindo este texto como fruto de uma pesquisa desenvolvida em rede pelo Grupo Internacional de Estudos e Pesquisas de Educação Superior (GIEPES - UNICAMP), que investiga o processo de internacionalização da Educação Superior no território ibero-americano. A pesquisa do GIEPES, intitulada "A Internacionalização na Educação Superior em Países da América Latina, Portugal e Espanha", conta com a participação de 22 universidades em nove países ${ }^{2}$.

Segundo as coordenadoras da pesquisa, Prof.a Dra. Elisabete Monteiro Aguiar Pereira e Prof. a Dra. Maria de Lourdes Pinto de Almeida, a investigação permitirá o conhecimento dos processos de internacionalização que estão acontecendo nas universidades dos diferentes países, bem como proporcionará um diálogo entre as experiências vividas por cada uma, no sentido da troca e da reflexão sobre essa atividade que será, cada vez mais, preponderante no cenário acadêmico contemporâneo (GIEPES, 2018, s/p).

A metodologia científica que norteou esta pesquisa foi a histórico-crítica (SAVIANI, 2013; CORSETTI, 2010). A abordagem de análise foi qualitativa utilizando como procedimentos metodológicos: a) pesquisa bibliográfica; b) análise documental (documentos institucionais da UNOESC); c) aplicação de questionário para análise de dados respectivos ao desenvolvimento dos processos de internacionalização das instituições integrantes da pesquisa.

O objetivo deste artigo consistiu em mapear e analisar os processos de internacionalização desenvolvidos em uma universidade caracterizada no modelo comunitário ${ }^{3}$, situada no oeste catarinense, a UNOESC. Dessa maneira, o texto

\footnotetext{
2 Países que integram a pesquisa em rede do GIEPES - UNICAMP a que este texto se refere: Argentina, Brasil, Colômbia, Chile, Espanha, México, Portugal, Uruguai, Venezuela. Mais informações disponíveis no site: https://www.giepes.fe.unicamp.br/br

${ }^{3}$ De acordo com a LDB 9.394, de 1996, artigo 20, as universidades comunitárias “[...] são instituídas por grupos de pessoas físicas ou por uma ou mais pessoas jurídicas, inclusive cooperativas de professores e alunos que incluam na sua entidade mantenedora representantes da comunidade" (BRASIL, 1996). O surgimento das universidades comunitárias no Brasil se deu a partir da segunda metade do século XX. Segundo Schmidt (2018, p. 38), as universidades comunitárias tiveram origem pela "[...] capacidade das organizações da sociedade civil e do poder público local de associar-se no esforço de suprir a lacuna de educação superior nas regiões interioranas". Em Santa Catarina, as universidades comunitárias começaram a ser constituídas na década de 1960, via fundações educacionais criadas pelos municípios.
} 
estrutura-se em duas partes: histórico da UNOESC e apresentação dos resultados da pesquisa sobre os processos de internacionalização.

\section{HISTÓRICO DA UNIVERSIDADE DO OESTE DE SANTA CATARINA (UNOESC)}

A UNOESC está no rol das Instituições Comunitárias de Ensino Superior (ICES). Sua trajetória se iniciou no final da década de 1960, em um período marcado por diversas mudanças no contexto sociopolítico e econômico da sociedade brasileira, decorrentes da implantação do regime empresarial militar e que impactaram a formulação da política econômica educacional, combinando propostas de modernização e expansão do Ensino Superior.

Assim nasceu o discurso da criação do modelo comunitário que foi implantado em Santa Catarina, o qual, para os autores Frantz e Silva (2002, p. 34), é fruto de "[...] uma iniciativa que não nasce no núcleo do poder público-estatal, mas na sua periferia, como expressão de vozes e vontades que querem se fazer ouvir e participar da construção de um espaço de educação socialmente mais amplo e democrático".

Bastiani e Trevisol (2018), ao analisarem o contexto de influência socioeconômica nacional na criação das universidades comunitárias em Santa Catarina, mencionam que o estado catarinense, ao optar pela criação das universidades comunitárias, fazendo uso da justificativa de buscar a interiorização do Ensino Superior e impulsionar o desenvolvimento econômico regional, na realidade, contribuiu para a expansão do setor privado.

Nesse cenário, a UNOESC foi fundada, a partir da unificação de três fundações educacionais existentes na região oeste que, criadas por leis municipais entre os anos de 1968 e 1974, partilhavam da mesma forma jurídica de criação, princípios e finalidades. São elas: Fundação Educacional do Oeste Catarinense (Fuoc), Fundação Educacional e Empresarial do Alto Vale do Rio do Peixe (Femarp) e a Fundação de Ensino para o Desenvolvimento do Oeste (Fundeste).

No movimento de unificação das fundações mantenedoras das Instituições de Ensino Superior da região oeste, a UNOESC se institucionalizou como uma universidade multicampi sob o modelo jurídico de IES comunitária e, em meados da década de 1990, foi reconhecida como universidade pelo Conselho Estadual de Educação, sendo credenciada pelo Ministério da Educação. 
Assim, sua localização foi estrategicamente projetada na mesorregião oeste, em cinco campi, nas cidades de Joaçaba, Videira, Xanxerê, São Miguel do Oeste e Chapecó, além de cinco unidades nos municípios de Capinzal, Campos Novos, Pinhalzinho, Maravilha e São José do Cedro, ofertando cursos de graduação, pós-graduação lato sensu e stricto sensu, nos quais desenvolve ações de internacionalização, cujos dados apresentam-se na sequência.

\section{OS PROCESSOS DE INTERNACIONALIZAÇÃO NA UNIVERSIDADE DO OESTE CATARINENSE}

A ideia de internacionalização e de formação acadêmica com uma visão mais ampla de mundo faz parte da constituição da universidade e, de acordo com o momento histórico vivido, as IESs foram se transformando e, junto delas, ocorreu também a modificação das práticas de internacionalização. Se no início da universidade essas ações se desenvolviam com objetivo principal voltado ao conhecimento, na contemporaneidade ganham importância os objetivos de ordem econômica, como a competividade, a visibilidade internacional e a lucratividade pela comercialização de serviços educacionais, os quais são fomentados pelo contexto globalizado.

Em relação à UNOESC, a interpretação conceitual da universidade para a internacionalização está presente no constructo do seu PDI (2018-2022), no qual a IES assume, oficialmente, a internacionalização como uma prioridade:

Na base da política de internacionalização assumida pela Unoesc encontra-se o desenvolvimento de parcerias internacionais que tragam diferenciação e qualidade na formação da sua comunidade acadêmica, construindo pontes indissociáveis do ensino, da pesquisa, da extensão e da inovação, com um olhar integrado, compartilhado e solidário de cooperação internacional. (UNOESC, 2018a, p. 56).

Assim, para os representantes da UNOESC, que trabalham na questão da internacionalização, a consolidação de processos internacionalizados tem por objetivo promover avanços da produção/socialização de conhecimento, de inovações tecnológicas e colocar a universidade em sintonia com a contemporaneidade via colaboração mútua, para o desenvolvimento de parcerias em pesquisas conjuntas, projetos, programas, educação continuada e qualificação de recursos humanos. 
Para tanto, com a finalidade de implementar as ações de internacionalização acadêmica, o Projeto Pedagógico Institucional (2018a, p. 44) expõe: “A UNOESC incentiva discentes e docentes a fazerem estudos em âmbito internacional, por meio da mobilidade acadêmica e de convênios com instituiç̧̃es de ensino superior de outros países".

As diretrizes políticas para desenvolver a internacionalização expostas no Projeto Pedagógico Institucional (2018a) são: disseminar a cultura da internacionalização no corpo social da IES; ampliar a inserção da instituição em redes de colaboração em âmbito internacional; promover a mobilidade estudantil; incorporar nos projetos pedagógicos dos cursos de graduação e pós-graduação a mobilidade acadêmica internacional.

Retomando o âmbito geral da pesquisa, observou-se que a internacionalização com o processo de globalização colocou as universidades diante de vários desafios e não cabe mais apenas entender o que ela significa, mas também desenvolvê-la de maneira institucionalizada, conforme pontua Pereira (2019, p. 4): "[...] trata-se de uma política de universidade que se baseia nos pilares da reciprocidade e da relevância acadêmica, promovida de forma que a instituição determine as necessidades e realidades específicas da sociedade de seu tempo histórico" .

Nesta mesma direção, Santos Filho (2018) alerta que, devido aos desafios e às mudanças que ocorreram no mundo com o processo de globalização, o entendimento conceitual de internacionalização ainda não está claro e precisa ser redefinido.

Outros autores, como Altbach e Knight (2007), Murphy (2007), Knight (2012) e Rumbley (2015), também apontam para a necessidade de entendimento da internacionalização nos níveis nacional, setorial e institucional, haja vista que, no contexto contemporâneo, sua abrangência conceitual envolve aspectos não apenas acadêmicos, mas também políticos, econômicos e socioculturais. Portanto, seguindo essa concepção, faz-se necessária uma outra definição, que, além de incluir esses níveis, seja capaz de refletir a realidade e os interesses institucionais. Correlacionando com os dados obtidos, foi notável que algumas universidades já citam esse pensamento como um possível conceito de internacionalização.

Além disso, essa nova definição, além de especificar as razões, benefícios e resultados dos processos de internacionalização (uma vez que esses elementos 
mudam de nação para nação e de instituição para instituição), precisa abranger três dimensões: internacional, intercultural e global, isto é, as relações entre nações, culturas e países. Essa definição é defendida por Knight (2003), quando enfatiza existir uma complementaridade entre esses três termos, que, juntos, expressam a riqueza da amplitude e da profundidade da internacionalização.

Diante do exposto, o que se constata em relação à categoria conceitual do objeto de investigação (na maioria das subcategorias) é a existência de uma dicotomia entre as definições de internacionalização, enfatizando falta de coerência entre as universidades. Isso deve ser motivo de reflexão, considerando que a internacionalização é vista como uma tendência comum a todas as universidades e, portanto, seu conceito necessita estar bem definido por cada uma delas.

Dando sequência, na segunda categoria da pesquisa, "Atuação Acadêmica", elencaram-se cinco subcategorias ${ }^{4}$ : graduação, pós-graduação, extensão, gestão e pesquisa, a fim de conhecer em quais âmbitos acadêmicos de atuação a internacionalização estava presente.

Analisando esta categoria, ficou evidente que as universidades estão em processo de adequação (haja vista a exigência da Capes para os programas de pós-graduação stricto sensu), já as subcategorias extensão e gestão são as menos desenvolvidas.

Neste sentido, um aspecto interessante a se ressaltar sobre as subcategorias é a questão da tríade universitária: ensino, pesquisa e extensão. Segundo Gumbowsky (2015), a universidade necessita atentar para o ensino, a fim de que não seja apenas uma mera transferência de conhecimento, mas um movimento voltado a ensinar tanto a pensar quanto a aprender, de modo que esses conhecimentos sejam revertidos em prol da sociedade. Com relação à pesquisa, a universidade deveria direcioná-la para o estudo, de modo que os sujeitos se tornem ativos no processo de aprendizagem e de construção do conhecimento. A pesquisa é uma ferramenta importante para esse processo, pois ela articula o trabalho realizado na universidade com os diversos setores da sociedade, gerando mudanças efetivas no entorno.

Quanto à extensão, Gumbowsky (2015) destaca que por meio dela é possível levar à comunidade os conhecimentos produzidos pela pesquisa, possibilitando

\footnotetext{
${ }^{4}$ Graduação: todas as universidades, exceto IUSUR; Pós-Graduação: todas as instituições; Pesquisa: todas as instituições; Extensão: UNICAMP, PUCV, UNOESC, FURB, UFGR, GRANADA, FURG.
} 
a socialização e democratização do conhecimento. Segundo o autor, esse é o verdadeiro sentido dos saberes produzidos na universidade, qual seja, contribuir para que o conhecimento seja difundido na sociedade.

A universidade que busca a integração do ensino, pesquisa e extensão reafirma seu compromisso social com as demandas da comunidade e busca incorporar essas demandas em seus currículos e ações, evitando assim o erro de distanciar-se das questões sociais e produzir conhecimento com baixa aplicabilidade prática. Os conhecimentos não devem estar restritos a área científica, ampliando para objetivos econômicos, políticos, sociais e culturais. (GUMBOWSKY, 2015, p. 13).

Diante do exposto, ressalta-se que a internacionalização, quando alicerçada ao tripé universitário, adquire seu verdadeiro sentido. Dessa forma, diferentemente do pensamento de autores como Santos e Almeida Filho (2012), que colocam a internacionalização como a "quarta missão da universidade", entendemos que ela se apresenta como um processo composto de ações e estratégias, que visa atender e servir ao ensino, à pesquisa e à extensão, sendo assim um meio, e não uma finalidade, e por isso nos aproximarmos de autores como Knight (2012), a qual afirma que "a internacionalização é um processo ou um meio de aprimorar ou atingir metas".

Pondera-se ainda que as IESs estão envoltas de muitas mudanças e, no que se refere à internacionalização, esta não pode assumir o posto de quarta missão da universidade, pois, conforme Knight (2012), a internacionalização "é um meio para se atingir um objetivo, e não uma finalidade em si mesma", portanto deve complementar o tripé da universidade.

Dando sequência à análise das categorias, na "Mobilidade", buscou-se investigar entre quatro subcategorias (discente, docente, pesquisadores e funcionários) quais delas são desenvolvidas pelas instituições ${ }^{5}$. Notadamente, a mobilidade discente e docente foram as mais referenciadas, estando presente em quase todas as instituições.

Para Rumbley (2015), a mobilidade acadêmica ainda é o tema mais relevante quando se trata de internacionalização, sendo também um poderoso parceiro

5Descrição das universidades que desenvolvem mobilidade dentro das quatro subcategorias: discente - todas as instituições, exceto IUSUR; docente - todas as instituições, exceto IUSUR, UNIOESTE, UPF; pesquisadores - UNICAMP, UA, UNTREF, UPN, Colima; funcionários - UNICAMP, UDELAR, UA, UNTREF, UPN. 
da globalização, pois, neste cenário hodierno, a mobilidade se consolida como uma estratégia importante que articula a internacionalização com movimentação econômica. Por esse motivo, essa modalidade de prática internacionalizada vem sendo fomentada mundialmente, tanto por organismos multilaterais e agências nacionais (como a Capes) quanto por instituições financeiras ${ }^{6}$.

Neste sentido, é importante salientar que as estratégias de internacionalização, entre elas a mobilidade, devem envolver aspectos voltados ao desenvolvimento do conhecimento (e não da economia e da competitividade entre as instituições), possibilitando maiores vínculos de pesquisa transnacionais, acordos/ parcerias entre instituições, docentes, pesquisadores e discentes.

Quanto à questão da mobilidade discente, desenvolvida pela UNOESC, pode-se evidenciar que a instituição começou a desenvolver essa prática no ano de 2010, quando implantou o Programa de Mobilidade Acadêmica, com o objetivo de desenvolver competências, habilidades profissionais, conhecimentos científicos e técnicos, valores e atitudes para o exercício da cidadania no Brasil e no exterior (UNOESC, 2018b). Destaca-se:

A Unoesc assumiu o compromisso com a internacionalização em 2010, quando criou o Programa de Mobilidade Acadêmica e instituiu coordenadoria específica para planejar e implementar ações estratégicas com essa finalidade e horizonte. Nesse novo momento da Instituição, deseja dar continuidade a esse trabalho, intensificando suas ações. Pela mobilidade acadêmica, a instituição deseja inserir-se na comunidade acadêmica internacional, comprometendo-se com a formação humana e profissional de seus discentes e docentes. (UNOESC, 2018b, p. 57)

Contudo, em 2018, quando a UNOESC implantou seu Plano de Internacionalização (PI), transformou o setor de mobilidade acadêmica em Coordenadoria de Relações Internacionais, sendo assim institucionalizado o órgão responsável pelo desenvolvimento dos processos de internacionalização da universidade.

Neste sentido, nota-se que, a partir do momento que uma universidade considera a internacionalização como prioridade, fortalece toda a comunidade

\footnotetext{
${ }^{6}$ Um exemplo de instituição financeira que fomenta a mobilidade acadêmica é o Santander, que em 2010 implantou um programa de concessão de bolsas para essa finalidade, apresentando três modalidades específicas de bolsas, a saber: Bolsa Programa Mobilidade Internacional; Bolsa Fórmula Santander e Bolsas Ibero-Americanas.
} 
acadêmica. Isso se expressa na reformulação tanto de seus documentos quanto de sua estrutura, conforme explicitam Gacel-Ávila e Rodriguez-Rodriguez (2018, p. 125):

[...] a internacionalização como prioridade institucional requer colocar em prática uma série de ajustes e reformas para as práticas institucionais, tais como a integração da dimensão internacional com os sistemas de planejamento, execução e desenvolvimento, elaboração de planos operacionais de internacionalização ligados às prioridades institucionais, identificação dos recursos financeiros e humanos necessários para assegurar a viabilidade e estabelecer critérios e procedimentos de avaliação quanto às políticas de internacionalização. (tradução nossa).

Conectando o excerto sobre as ações internacionalizadas constituírem-se como prioridade institucional, outro aspecto relevante evidenciado na pesquisa é que a mobilidade foi considerada pelas universidades investigadas a principal prática internacionalizada e também como sinônimo de internacionalização.

Ademais, partindo do pressuposto de que a mobilidade não se constitui como um fenômeno recente, mas que foi adquirindo arranjos a partir das intencionalidades das IES, em não somente deslocar estudantes de um país a outro, mas consolidar modelos de formação diferenciados, conectados com o conhecimento em nível global, entende-se que ela não é sinônimo de internacionalização, mas uma complexa ação que necessita ser planejada e executada com eficiência.

Ao encontro do exposto, Stallivieri (2009, p. 12) alude que "[...] a formação em nível de graduação e pós-graduação com complementação no exterior passou a ser muito valorizada em função do perfil profissional que está sendo solicitado pelo mercado". De acordo com a autora, a mobilidade é uma ferramenta utilizada pelas IESs que precisa ser realizada com muito cuidado, pois contribui para formar profissionais aptos a outras culturas com competências específicas na sua área do conhecimento.

Diante desse contexto, as universidades, buscando atrair cada vez mais acadêmicos e, ao mesmo tempo, alcançar maior projeção internacional, buscam alternativas de atratividade para seus cursos, via internacionalização, investindo na mobilidade acadêmica.

Esse cenário pode ser observado na UNOESC, que, segundo seus representantes, na expectativa de ampliação dos objetivos das suas políticas comunitárias, 
via plano de internacionalização, vem organizando sua estrutura administrativa e acadêmica para dar conta das exigências dos programas internacionais e fortalecer os processos de mobilidade acadêmica dos seus discentes, docentes e funcionários.

Neste sentido, a mobilidade dos docentes e funcionários da UNOESC acontece via participação em processos de seleção ofertados pela Capes: Programa de Pós-Doutorado no Exterior, Doutorado-Sanduíche no Exterior (PDSE), Estágio Sênior, Pesquisa Pós-Doutoral, Programa Ciência sem Fronteiras (pós-doutorado), Programa e Apoio a Eventos no País (PAEP) e Apoio a Evento no Exterior (AEX).

Diante de tal realidade, evidencia-se que a UNOESC necessita consolidar sua política de internacionalização para que possa expandir suas ações no tocante à mobilidade acadêmica (em todas as modalidades), mas visando não apenas à inserção da universidade no cenário mundial econômico, como também à expansão das fronteiras do conhecimento e da cultura, uma vez que, conforme expresso no seu PDI e PI, a universidade apresenta-se "comprometida" com a internacionalização, a fim de servir às suas finalidades como instituição comunitária.

Seguindo as análises das categorias, na quarta denominada de "Currículo", analisaram-se os aspectos formativos curriculares mencionados nas definições de internacionalização das instituições. Dessa forma, elencaram-se as seguintes subcategorias $^{7}$ : duplo diploma; aulas em idioma estrangeiro; cotutela; convalidação de créditos de graduação e pós-graduação; oferta de cursos de línguas para estudantes; alunos estrangeiros; professores estrangeiros; doutorado-sanduíche e processos de acreditação do Espaço Europeu de Educação Superior.

Neste aspecto, a UNOESC não apresenta internacionalização em nenhuma das subcategorias. Com relação às demais universidades, foi notável que, em sua maioria, oferecem cursos de línguas para os estudantes e possuem tanto alunos

\footnotetext{
${ }^{7}$ Abrangência do currículo em cada subcategoria: duplo diploma - UNICAMP, PUCV, FURG, Colima, UFRG, FURB; aulas em idioma estrangeiro - Colima, UA, FURG, FURB; cotutela - UNICAMP, PUCV, Colima, FURG; convalidação de créditos graduação e pós-graduação - UNICAMP, Colima, Granada, UA, FURB, FURG; oferta de cursos de línguas para estudantes - UNICAMP, Colima, Granada, URI, UA, UNTREF, IUSUR, FURG, FURB; alunos estrangeiros - UNICAMP, Granada, FURB, UDELAR, IUSUR, UNIOESTE, UNTREF, UFRG, FURG, UA, LUZ; professores estrangeiros - UNICAMP, UDELAR, IUSUR, UFRG, FURG, UA, FURB; doutorado-sanduíche - UNICAMP, FURG; processos de acreditação do Espaço Europeu de Educação Superior - UA, Granada.
} 
quanto professores estrangeiros. Entretanto foi perceptível que aspectos como aulas em idioma estrangeiros, doutorado-sanduíche e processos de acreditação do Espaço Europeu de Educação Superior necessitam ser mais bem desenvolvidos pelas universidades.

Moreira (2012) reafirma esse mesmo ponto de vista, ao destacar que a internacionalização do currículo implica um trabalho conjunto de estudiosos de diferentes países, com a intenção de configurar um campo que se caracterize por uma perspectiva transnacional, mas não uniforme. Ainda, esse autor pondera a importância da seguinte compreensão sobre a internacionalização no campo do currículo:

[...] (a) se aplica a práticas sociais que não visam à homogeneização do campo; (b) não se limita ao simples movimento de teorias e práticas de um país para outro; (c) se desenvolve no longo prazo e implica uma disposição para ensinar e aprender com outras nações; (d) provoca mudanças no pensamento e nas atitudes dos indivíduos, no esforço por configurar um território comum; (e) apresenta dimensões sociais, culturais, morais, éticas e políticas que transcendem o estreito foco econômico e estabelecem uma sinergia com outras agendas; (f) não se expressa apenas por meio de intenções democráticas e neutras: relações de poder estão necessariamente envolvidas e devem ser avaliadas quando se considerarem as questões curriculares; (g) tanto pode corresponder a tentativas de promovê-la junto a instituições ou indivíduos, quanto à intenção de analisar seus efeitos nas teorias, práticas e políticas educacionais. (MOREIRA, 2012, p. 219).

Já para a autora Leask (2009) é importante também refletir sobre dois conceitos próximos, mas que possuem algumas diferenças, a saber: o conceito de currículo internacionalizado e internacionalização do currículo.

Nessa linha de entendimento, a internacionalização do currículo é a possibilidade de incorporar ao conteúdo, ao ensino, à aprendizagem e aos instrumentos de avaliação as dimensões interculturais internacionais, enquanto o currículo internacionalizado envolve (internacionalmente) os estudantes com a pesquisa e com a diversidade linguística e cultural, desenvolvendo suas perspectivas interculturais e internacionais como cidadãos e profissionais globais.

Diante dessas duas definições, pondera-se que ambas possuem semelhanças no sentido de que, quando o currículo é colocado em ação nas instituições, na perspectiva da internacionalização, possibilita aos estudantes conhecimentos e 
competências demandadas pelos padrões internacionais. Em geral, instituições com projetos que prospectam essa direção assumem como propósito acadêmico preparar seus estudantes para que, em contextos internacionais e multiculturais, desempenhem eficientemente suas atividades - sejam elas pessoais, sejam elas profissionais (THIESEN, 2017, p. 999).

Para o caso do Brasil, segundo Thiesen (2017, p. 1008-9), diversas ações educacionais relacionadas à internacionalização estão articuladas ao contexto internacional orientado por organismos multilaterais e possuem efeitos que implicam alguma medida sobre os currículos, tais como: implantação do Programa Ciência sem Fronteiras (CSF); concessão de bolsas para estudos no exterior nas etapas da graduação e pós-graduação stricto sensu; criação de redes de pesquisa em âmbito internacional; espaços que estimulam maior mobilidade estudantil e de docentes; implantação dos programas Idiomas sem Fronteiras (ISF) e Licenciaturas Internacionais (PLI); entre outros.

Considerando os apontamentos, é necessário que as universidades fiquem atentas à distinção entre currículo internacionalizado e internacionalização do currículo, sendo que o primeiro é o produto e o segundo o processo. Isso significa que é preciso considerar no processo de internacionalização do currículo os resultados e as contribuições dadas à aprendizagem.

Na categoria "Estrutura Organizacional"8, são englobadas todas as menções referentes à existência de um órgão próprio para a internacionalização, site em outros idiomas, visitas internacionais, formação de funcionários bilíngues e adequação de documentos acadêmicos.

Analisando os dados obtidos na pesquisa, percebe-se que as universidades necessitam, de maneira geral, de adaptação quanto à formação de funcionários bilíngues e aos documentos acadêmicos. Em relação à UNOESC, ressalta-se que esta apresenta órgão próprio para internacionalização.

\footnotetext{
${ }^{8}$ Instituições que apresentam as subcategorias referentes à categoria "Estrutura Organizacional": órgão próprio para a internacionalização - UNICAMP, UNOESC, Colima, URI, Granada, UFMS, UPF, FURB, UNTREF, PUCV, IUSUR, UDELAR, UA, LUZ, UPN, UNIOESTE, UFSM, FURG; sites em outros idiomas - UNICAMP, Colima, UFRG, FURB, IUSUR, PUCV, UPF, URI, Granada, UFSM, FURG (somente na pós-graduação), UA; visitas internacionais - UNICAMP, Colima, Granada, FURB, UFRG, UPF, UNOESC, URI, UDELAR, FURG, UA; formação de funcionários bilíngues - UNICAMP, Colima, FURG; adequação de documentos acadêmicos - UNICAMP, FURG.
} 
Quanto às subcategorias citadas, na UNOESC destaca-se que a universidade procura implementar projetos que propiciem seu avanço, materializando essas intenções em documentos institucionais e especialmente com o projeto que representa o "carro-chefe" da universidade no quesito internacionalização, o Programa de Mobilidade Acadêmica, pelo qual a instituição assumiu o compromisso com o desenvolvimento e a formação humana dos alunos e docentes em nível tanto local quanto global (UNOESC, 2018b).

Ainda em relação à categoria "Estrutura Organizacional", valorosas são as ponderações de Knight (2012) quanto à necessidade de a universidade analisar suas particularidades para a definição, implantação e avaliação de estratégias de internacionalização a serem adotadas. Segundo a autora, para a eficiência do desenvolvimento das práticas internacionalizadas, também é necessário o entendimento de que tais ações sejam parte de um processo adaptável. Nas palavras da autora: "[...] trata-se de um processo de mudança adaptado para atender necessidades e interesses individuais de cada instituição" (KNIGHT, 2012, p. 2).

Na sexta categoria, que diz respeito à "Produção de Conhecimento", elencaram-se quatro grandes conceitos, que são: pesquisa conjunta, redes de pesquisa, publicação conjunta e publicação em periódicos estrangeiros. Neste quesito, como resultado, evidencia-se que a UNOESC apresenta pesquisa conjunta e redes de pesquisa e publicação conjunta, faltando somente aumentar expressivamente o número de publicações em periódicos estrangeiros.

Dando continuidade à análise, na sétima categoria investigaram-se as universidades que participam de eventos internacionais. Obteve-se resposta afirmativa em relação a este tópico; de uma maneira ou outra, todas as instituições participam e/ou realizam eventos de caráter internacional.

E, por fim, na última categoria, "Dimensão Prospectiva", questionou-se sobre as manifestações expressas pelas universidades quanto às intenções de organização de atividades consideradas chaves para o futuro. Sobre esta questão, os resultados da análise do formulário levaram a uma subdivisão em três subcategorias, sendo elas: compatibilização de currículos entre instituições; ampliação da visibilidade internacional e ampliação de parcerias internacionais. Nesta resposta, a UNOESC apresentou como destaque: compatibilização de currículos entre instituições e ampliação de parcerias internacionais. 
Outro dado importante a mencionar para essa categoria no caso da UNOESC é que em seu PI são prospectadas metas a serem alcançadas até 2022, as quais contemplam os aspectos da qualificação da prática de idiomas estrangeiros, a promoção de cursos e eventos sobre internacionalização, maior desenvolvimento de atividades técnico-científicas, oferta de cursos em regime de cotutela e dupla titulação simultânea e, ainda, o incremento/incentivo a publicações em periódicos do exterior e coautoria com autores estrangeiros.

\section{CONSIDERAÇÕES FINAIS}

Neste estudo, apresentou-se, entre outros aspectos, a complexa relação existente entre internacionalização da Educação Superior e globalização. E, pela análise tanto em âmbito geral das 22 universidades integrantes da pesquisa do GIEPES - UNICAMP quanto especificamente da UNOESC, foi possível evidenciar que a conceituação da temática investigada apresenta muitas similaridades, entre elas, o próprio conceito contemporâneo do que representa a internacionalização, como também que a prática mais desenvolvida é a mobilidade acadêmica de discentes e docentes.

Outros programas aderidos pela universidade como práticas internacionalizadas foram: Ciência sem Fronteiras, do Ministério da Ciência, Tecnologia e Inovação, o qual oportunizou o intercâmbio de alunos tanto na modalidade de cotas da IES quanto de candidaturas individuais; e o Programa Estudantes Convênio de Graduação - do MEC.

Ainda em tempo, na primeira categoria de análise, destaca-se, no caso da UNOESC, a implantação do Plano de Internacionalização (PI) no ano de 2018, o qual apresenta metas e prazos que visam fortalecer e expandir suas ações internacionalizadas, permeando, além dos cursos de graduação, os programas de pós-graduação stricto sensu. Destaca-se:

O objetivo principal do Plano de Internacionalização consiste em apresentar uma proposta de planificação da internacionalização da Universidade do Oeste de Santa Catarina que permita a instituição organizar e priorizar suas ações, com objetivos, metas e recursos, visando à internacionalização do ensino superior e da pesquisa. (UNOESC - Pl, 2018b, p. 4)

Contudo, neste documento (UNOESC, 2018b), a universidade faz uso dos termos globalização, inovação e tecnologia, o que vai ao encontro das tendências 
internacionais que atrelam os processos de internacionalização ao contexto da globalização.

Destaca-se também que a UNOESC é definida como uma Instituição Educacional Multicampi (UNOESC, 1991, p. 15), que tem como missão ser centro de referência para o oeste catarinense, buscando a formação profissional e humana, por meio do ensino, da pesquisa e da extensão, gerando conhecimento para um desenvolvimento regional sustentável (UNOESC, 2018a). E, partindo desse parâmetro, a construção dessa instituição em modelo multicampi se deu devido às exigências do meio, adequando-se às necessidades da sociedade da época.

Assim, diante do cenário hodierno, fica evidente que a UNOESC, conforme os dados analisados, está atenta e consciente da necessidade de adaptação cada vez maior ao contexto globalizado e que uma das vias na contemporaneidade é o fortalecimento dos seus processos de internacionalização.

Sob esse mesmo aspecto, todas as IESs integrantes da pesquisa demonstram a compreensão de que a globalização modificou o cenário de busca pelo conhecimento e esse é um dos motivos que se exigiu adaptação (por parte das universidades) à internacionalização.

Além de desenvolver internacionalização pela mobilidade, voltada aos discentes e docentes, a UNOESC também promove ações com relação aos currículos, por meio da compatibilização curricular com instituições que possui parcerias.

Ainda, pela análise dos dados, evidenciou-se que a UNOESC desenvolve pesquisas e publicações conjuntas e participa de redes de pesquisa. Outrossim, possui um órgão próprio para a internacionalização, nomeado Coordenadoria de Relações Internacionais, e realiza visitas internacionais.

Diante desse cenário, vale a pena destacar que a UNOESC está implantando e fortalecendo gradativamente os processos que envolvem a internacionalização, contudo se alerta para a tendência (e isso se aplica a todas as instituições) de resumir a internacionalização apenas a aspectos de mobilidade. Isso pode levar à sintetização das IESs como mercadorias internacionais, o que não deve se configurar como sentido e propósito da internacionalização.

Sendo assim, foi perceptível que, para as universidades integrantes da pesquisa, e nisto incluímos a UNOESC, a internacionalização não é uma opção, mas sim "[...] um movimento que emerge no contexto da sociedade globaliza- 
da" (MOROSINI; DALLA CORTE, 2018, p. 116), a partir das recomendações de organismos internacionais, das regulações avaliativas da Capes e das próprias necessidades institucionais em manter-se ativa, tanto na captação de alunos quanto no interesse de professores e pesquisadores em desenvolver parcerias com a universidade.

\section{REFERÊNCIAS}

ALTBACH, P. G.; KNIGHT, J. Visión panorámica de la internacionalización en la educación superior: motivaciones y realidades. Journal of Studies in International Education, México, v. 11, n. 3-4, p. 290-305, Fall/Winter 2007.

BASTIANI, S. C.; TREVISOL, J. V. A expansão da educação superior presencial em Santa Catarina (1990-2016). Revista Internacional de Educação Superior, São Paulo, v. 4, n. 3, p. 558-79, set./dez. 2018.

BRASIL. Lei n. 9.394, de 20 de dezembro de 1996. Estabelece as diretrizes e bases da educação nacional. Diário Oficial da União, Brasília, DF, 23 dez. 1996.

CORSETTI, B. A metodologia histórico-crítica e a reflexão sobre a questão do rendimento escolar no Brasil. In: MARTINS, A. M.; WERLE, F. O. C. Políticas educacionais: elementos para reflexão. Porto Alegre: Redes Editora, 2010.

FRANTZ, W.; SILVA, E. As funções sociais da universidade: o papel da extensão e a questão das comunitárias. ljuí, RS: Editora Unijuí, 2002.

GACEL-ÁVILA, J.; RODRIGUEZ-RODRIGUES, S. Internacionalización de la educación superior en América Latina y el Caribe: un balance. México: Unesco-lesalc, 2018.

GRUPO INTERNACIONAL DE ESTUDOS E PESQUISA EM EDUCAÇÃO SUPERIOR (GIEPES). Giepes. Campinas, SP, 2018. Disponível em: https://www.giepes.fe.unicamp.br/br/sobre. Acesso em: 15 maio 2018.

GUMBOWSKY, A. A internacionalização do ensino superior: desafios das universidades fundacionais catarinenses. Santa Cruz do Sul, RS, 2015. Disponível em: http://online. unisc.br/acadnet/anais/index.php/sidr/article/viewFile/13330/2496

KNIGHT, J. Five truths about internationalization. International Higher Education, Boston, n. 69, p. 1-4, Fall 2012. Disponível em: https://ejournals.bc.edu/ojs/index.php/ihe/article/ view/8644/7776 
KNIGHT, J. Updating the definition of internationalization. International Higher Education, Boston, n. 33, p. 2-3, Fall 2003.

LEASK, B. Using formal and informal curricula to improve interactions between home and international students. Journal of Studies in International Education, v. 13, n. 2, 205-21, jan. 2009.

MOREIRA, A. F. B. O atual processo de internacionalização do campo do currículo, estratégias e desafios. Educação, Sociedade \& Culturas, n. 37, 2012. Disponível em: https://www.fpce.up.pt/ciie/sites/default/files/ESC37_A_Moreira.pdf

MOROSINI, M. C.; DALLA CORTE, M. G. Teses e realidades no contexto da internacionalização da educação superior no Brasil. Revista Educação em Questão, Natal, RN, v. 56, n. 47, p. 97-120, jan./mar. 2018.

MURPHY, M. Experiences in the internationalization of education. Strategies to promote equality of opportunity at Monterrey Tech. Higher Education, v. 53, n. 2, p. 167-298, 2007.

PEREIRA, E. M. A. Internacionalização na universidade contemporânea: uma visão da internacionalização em uma universidade pública paulista. Revista Internacional de Educação Superior, Campinas, SP, v. 5, p. 1-19, 2019.

RUMBLEY, L. E. Intelligent internationalization: a 21st century imperative. International Higher Education, n. 80, p. 16-7, Spring, 2015. DOI: https://doi.org/10.6017/ ihe.2015.80.6146

SANTOS, F. S.; ALMEIDA FILHO, N. A quarta missão da Universidade: internacionalização universitária na sociedade do conhecimento. Brasília: Editora Universidade de Brasília; Coimbra: Imprensa da Universidade de Coimbra, 2012.

SANTOS FILHO, J. C. Entrevista com o Prof. Dr. Jose Camilo dos Santos Filho. Revista de Ciências Humanas, Frederico Westphalen, RS, v. 19, n. 2, p. 168-80, maio/ago. 2018.

SAVIANI, D. Pedagogia histórico-crítica: primeiras aproximações. 11. ed. rev. Campinas, SP: Autores Associados, 2013.

SCHMIDT, J. P. Universidades comunitárias e terceiro setor: fundamentos comunitaristas da cooperação em políticas públicas. Santa Cruz do Sul, RS: EDUNISC, 2018. 
STALLIVIERI, L. As dinâmicas de uma nova linguagem intercultural na mobilidade acadêmica internacional. 2009. Tese (Doutorado em Línguas Modernas) - Universidad del Salvador, Buenos Aires, 2009.

THIESEN, J. S. Internacionalização dos currículos na educação básica: concepções e contextos. Revista e-Curriculum, São Paulo, v. 15, n. 4, p. 991-1017, out./dez. 2017.

UNIVERSIDADE DO OESTE DE SANTA CATARINA (UNOESC). Plano de Desenvolvimento Institucional - PDI (2018-2022). 3. ed. Joaçaba, SC: Editora da Unoesc, 2018a.

UNIVERSIDADE DO OESTE DE SANTA CATARINA (UNOESC). Plano de Internacionalização - PI (2018-2022). 1. ed. Joaçaba, SC: Editora Unoesc, 2018b.

UNIVERSIDADE DO OESTE DE SANTA CATARINA (UNOESC). Projeto de Universidade. Fundação Educacional Unificada do Oeste de Santa Catarina: Joaçaba/Chapecó/Videira. Porto Alegre: Evangraf, 1991.

\section{Sobre os autores:}

Maria de Lourdes Pinto de Almeida: Pós-doutora em Políticas Educacionais pela Universidade de São Paulo (USP) e em Ciência, Tecnologia e Sociedade pela Universidade Estadual de Campinas (Unicamp). Doutora e mestre em Filosofia, História e Educação pela Faculdade de Educação da Unicamp. Graduada em Pedagogia pela Unicamp. Graduada em História pela Faculdade de Ciências e Letras Plínio Augusto do Amaral. Pesquisadora do Grupo Internacional de Estudos e Pesquisas em Ensino Superior (GIEPES), da Faculdade de Educação da Unicamp. Docente pesquisadora do PPGE da Universidade do Oeste de Santa Catarina (UNOESC), na linha de pesquisa Educação, Políticas Públicas e Cidadania. Pesquisadora da Universidade Virtual do Estado de São Paulo. Pesquisadora colaboradora do PPGEd da Universidade Regional Integrada do Alto Uruguai e das Missões (URI) do RS, campus Frederico Westphalen, na função de coordenadora de Produção Científica. Diretora da Rede Iberoamericana de Estudos e Pesquisas em Políticas e Processos de Educação Superior (RIEPPES) sediada na UNOESC, que tem parceria com o GIEPES da UNICAMP. Coordenadora adjunta do GIEPES - UNICAMP. Coordenadora do Grupo de Estudos e Pesquisas em Políticas de Educação Superior da região Sul (GEPPES - Sul), vinculado ao GIEPES - UNICAMP.

E-mail:malu04@gmail.com, Orcid: http://orcid.org/0000-0001-8515-2908 
Silmara Terezinha Freitas: Mestre em Educação pela Universidade do Oeste de Santa Catarina (UNOESC). Especialista em Coordenação Pedagógica pela Universidade Federal de Santa Catarina (UFSC).E-mail: silmara.fisica@gmail.com, Orcid: https://orcid.org/0000-0003-1657-4781

Diego Palmeira Rodrigues: Doutorando e mestre em Educação pela Universidade do Oeste de Santa Catarina (UNOESC). Técnico em Assuntos Educacionais da Universidade Federal da Fronteira Sul (UFFS).E-mail: diegopalmeirarodrigues@ gmail.com, Orcid: https://orcid.org/0000-0002-2431-654X

Recebido em 15 de outubro de 2019

Aprovado em 14 de fevereiro de 2020 